\title{
Topographic influences on recent changes of very small glaciers in the Monashee Mountains, British Columbia, Canada
}

\author{
Christopher M. DeBEER, ${ }^{1}$ Martin J. SHARP ${ }^{2}$ \\ ${ }^{1}$ Centre for Hydrology, University of Saskatchewan, 117 Science Place, Saskatoon, Saskatchewan S7N 5C8, Canada \\ E-mail: cmd225@mail.usask.ca \\ ${ }^{2}$ Department of Earth and Atmospheric Sciences, University of Alberta, 1-26 Earth Sciences Building, Edmonton, \\ Alberta T6G 2E3, Canada
}

\begin{abstract}
An analysis of the local topographic setting of very small $\left(<0.4 \mathbf{k m}^{2}\right)$ glaciers within a small region of the Monashee Mountains, British Columbia, was conducted to investigate its influence on recent changes in the extent of these glaciers. Net changes in glacier extent were determined from a detailed manual comparison of remotely sensed imagery acquired in 1951, 2001 and 2004. Most of the 86 glaciers included in the study showed no observable net change in area over the study period, while six glaciers retreated, four disappeared entirely and only one advanced. Indices derived to characterize elements of the local topographic setting that might affect the local mass balance suggest that most of the glaciers are situated in locations that favor ice preservation by enhancing mass input and/or reducing ablation rates. Glaciers situated in less favorable settings generally either decreased in area or disappeared. The results suggest that most of the glaciers studied have retreated as far as they are likely to under the climatic conditions of the late 20th century.
\end{abstract}

\section{INTRODUCTION}

Interest in the fluctuations of alpine glaciers in response to climate change has increased in recent years. Alpine glaciers are an important source of water, augmenting the flow of streams and rivers during warm and dry periods (Fountain and Tangborn, 1985), and ice loss from these glaciers makes a significant contribution to global sea-level rise (Braithwaite and Raper, 2002; Dyurgerov and Meier, 2005; Meier and others, 2007). Documentation of changes in these glaciers and explanation of how they vary with glacier size is critical to understanding the linkages between climate changes and glacier variations. A number of research initiatives focused on western Canada, such as the Western Canadian Cryospheric Network $\left(\mathrm{WC}^{2} \mathrm{~N}\right)$, are presently engaged in these types of analyses.

Several regional studies of glacier area changes within western North America present conflicting evidence about the response of the smallest glaciers to recent climate changes (i.e. increasing air temperature and reduced winter precipitation). Some suggest that the smaller glaciers (i.e. $<\sim 0.5 \mathrm{~km}^{2}$ ) proportionally are most affected by recent climate variations (e.g. Granshaw and Fountain, 2006; Demuth and others, 2008; personal communication from B. Menounos, 2008), while others report very limited changes in the area of smaller glaciers (e.g. DeBeer and Sharp, 2007; Hoffman and others, 2007). This poses a dilemma since estimates or predictions of ice loss at regional scales are dependent on how relative changes in glacier area (i.e. when tabulated according to initial size) vary across the size-class distribution of glaciers. Significant uncertainties arise when making inferences about changes in regional- or global-scale glacier extent on the basis of small, and possibly unrepresentative, samples (http://environmentalresearchweb.org/cws/article/opinion/35103). Therefore, there is a need to reconcile these apparently contradictory results, which may be at least partly due to differences in the time periods over which changes were measured or to differences in the data sources and methodologies utilized by the various studies. Alternatively, small glaciers in different mountain ranges may indeed have undergone differing amounts of relative area change in recent decades. Since very small glaciers represent a large portion of the glacier population in western North America and in many other parts of the world, it is important that we understand the causes of these apparent differences in their behavior.

DeBeer and Sharp (2007) argued that the very limited area changes of the smallest glaciers in the southern Canadian Cordillera could be explained by the topographic settings in which most of these glaciers were located. They suggested (but did not demonstrate) that these glaciers are typically found in sheltered sites where conditions are favorable for their preservation, or that they have relatively high mean elevations and do not extend far down-valley to elevations where melt rates would be large. This study evaluates this suggestion more rigorously by examining the local topographic setting of very small $\left(<0.4 \mathrm{~km}^{2}\right)$ glaciers and their net area changes over the period 1951-2001 in a small region of the Canadian Cordillera, the southern Monashee Mountains.

\section{STUDY AREA}

This study focused on a relatively small $\left(\sim 800 \mathrm{~km}^{2}\right)$ region of the Monashee Mountains (part of the broader Columbia Mountains) in the southeastern interior of British Columbia (Fig. 1). These mountains consist of sharp-crested peaks and arêtes sculpted by cirque glaciers (Holland, 1976), with relief of up to $\sim 2400 \mathrm{~m}$ between the highest peaks and the Columbia River valley to the east. The eastern slopes of the Monashees drain into the Columbia River and the western slopes feed into tributaries of the Shuswap River and the Upper Fraser River system. The Monashee Mountains are influenced by both maritime and continental air masses, and the distribution of precipitation throughout the year is relatively uniform. Total annual precipitation ranges from 1000 to $1500 \mathrm{~mm}$ over these mountains based on climatic normals for 1941-70 (Farley, 1979). At low elevations, 


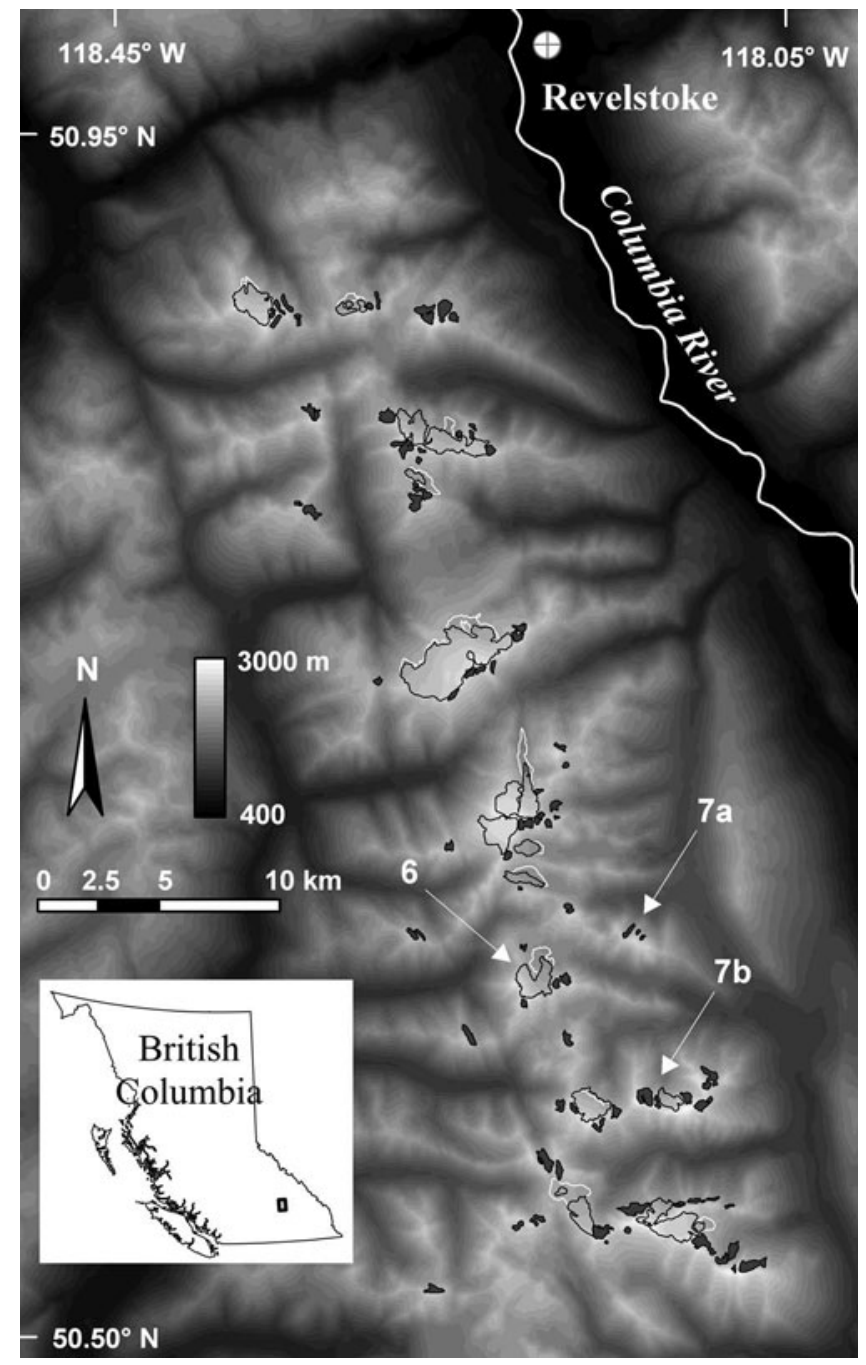

Fig. 1. Topographic map of the study region within the southern Monashee Mountains. Gray filled polygons represent very small glaciers selected for topographic analysis; glaciers initially $>0.4 \mathrm{~km}^{2}$ in the region are represented as open polygons (white lines: 1951 margins; black lines: 2001 margins). The locations of the features in Figures 6 and $7 \mathrm{a}$ and $\mathrm{b}$ are denoted by the arrows. Inset map shows the location of the study region within the province of British Columbia.

winter temperature (January average of -10 to $-15^{\circ} \mathrm{C}$ ) is moderated by the influence of maritime air, but July mean temperatures range from 15 to $20^{\circ} \mathrm{C}$ due to reduced westerly airflow and greater influence of continental air masses at this time of year (Farley, 1979; Environment Canada, http:// www.cccma.ec.gc.ca/hccd/).

\section{METHODS AND ANALYSIS}

\section{Data sources and image processing}

The data used in this study consist of a Landsat 7 Enhanced Thematic Mapper Plus (ETM+) image, British Columbia Government aerial photography and a DMTI Spatial Inc. $30 \mathrm{~m}$ resolution digital elevation model (DEM). The ETM+ scene was acquired on 14 September 2001 (path 44, row 25) and was obtained from the Geogratis website of Natural Resources Canada (http://geogratis.cgdi.gc.ca/) as Landsat 7 Orthorectified Imagery over Canada. This imagery is derived from Landsat 7 raw image level L1G (i.e. radiometrically and systematically corrected) processed data and is reported to have a horizontal positional accuracy of $\pm 30 \mathrm{~m}$ or less with a $90 \%$ level of confidence. The aerial photography was acquired on 17 September 1951 along British Columbia flight-lines 1393 and 1394, which were flown at an altitude of $\sim 5300 \mathrm{~m}$. The focal length of the camera was $81.38 \mathrm{~mm}$, resulting in an average photographic scale of $\sim 1: 50000$. The original aerial photography prints are archived at Canada's National Hydrology Research Institute (NHRI) at the University of Saskatchewan as part of the National Glacier Inventory and were digitally scanned at a resolution of 300 dpi using a flatbed scanner. This resulted in a ground resolution of the digital aerial photograph images of $\sim 4 \mathrm{~m}$. As small features such as trees and small boulders could be clearly distinguished in the digital imagery, the true image resolution is likely finer than this value. The DMTI Spatial Inc. DEM was derived from interpolation of the Canadian National Topographic Database (NTDB) digital mapping, which in turn corresponds to the National Topographic System (NTS) 1 : 50000 scale map sheets (82L09 and 82L16 for the study region). Topographic contours for this region correspond to the first-edition NTS sheets, which were based on aerial photography flown in 1947 and 1951. However, vertical accuracy is not reported, so the error is estimated to be approximately $\pm 20 \mathrm{~m}$, or half of the NTDB contour interval. The DEM was obtained through the data and Geographic Information System (GIS) services of the University of Alberta Library.

The ETM+ Orthorectified Imagery was obtained with spatial reference to the Lambert Conformal Conic map projection with standard parallels of $49^{\circ}$ and $77^{\circ} \mathrm{N}$ on the North American Datum 1983 (NAD83) datum and Geodetic Reference System 1980 (GRS80) ellipsoid, and subsequently projected in Universal Transverse Mercator (UTM) coordinates. Data fusion was performed to enhance the apparent resolution of the imagery using $\mathrm{PCl}$ Geomatica ${ }^{\mathrm{TM}}$. In this process, an input pseudo-color image is fused with a grayscale intensity image to produce an output RGB (red, green, blue) pseudo-color image with the same resolution as the original grayscale image. ETM+ bands 2, 3 and 4 $(\lambda=0.53-0.61,0.63-0.69$ and $0.78-0.90 \mu \mathrm{m} ; 30 \mathrm{~m}$ resolution) were combined with panchromatic band 8 ( $\lambda=0.52-0.90 \mu \mathrm{m} ; 15 \mathrm{~m}$ resolution).

The digital aerial photographs were spatially referenced to the fused ETM+ Orthorectified Imagery using the thinplate spline mathematical model in PCI Orthoengine ${ }^{\mathrm{TM}}$. This model fits the ground control points (GCPs) exactly, and warping is distributed throughout the image, with minimum curvature becoming linear away from the GCPs. Photographs essentially centered on individual glaciers, or groups of glaciers, were georeferenced by selecting 10-20 GCPs that were clearly identifiable in both images, with points chosen on stable terrain directly adjacent to, and surrounding, the glacier margins. This approach is well suited to the purposes of this study, as it allows a high level of accuracy over the small areas occupied by the glaciers of interest, with relatively few points collected in a dense network immediately surrounding the glaciers.

A further source of high-resolution imagery was used as visual reference to help positively identify glaciers and distinguish snowpatches near the time of the ETM+ image acquisition. This imagery is made available for public viewing through the Google $\mathrm{e}^{\mathrm{TM}}$ Earth web application, which displays British Columbia Government Terrain Resources 
Information Management (TRIM) orthophoto mosaic imagery over the study region $(0.5 \mathrm{~m}$ resolution). For this region, the imagery was derived from aerial photography acquired in the late summer of 2001 and 2004. Digital scanned photographs were orthorectified using available camera calibration reports, interior orientation data (i.e. fiducial marks), and absolute orientation data consisting of a minimum of six GCPs, together with parameters for Earth curvature, terrain distortions and refraction resulting from aerial triangulation, in the adjustment package (as documented within the British Columbia Crown Registry and Geographic Base web page, http://ilmbwww.gov.bc.ca/ bmgs/). The documented horizontal error of the product is stated to be a maximum of $0.5 \mathrm{~mm}$ for the final map scale (i.e. $10 \mathrm{~m}$ for $1: 20000$ scale TRIM mapping). Google $\mathrm{T}^{\mathrm{TM}}$ Earth also allows three-dimensional (3-D) perspective viewing of the imagery by draping it over a DEM (assumed in this case to be a subset of the regional TRIM DEM).

\section{Glacier delineation and change detection}

Ice margins were delineated from the 2001 ETM+ imagery and the georeferenced 1951 aerial photography using onscreen digitizing techniques in ESRI® $\operatorname{ArcMap}^{\text {TM }}$ 9.1 GIS. Glaciers were defined by manually digitizing a series of points along the ice margins to construct a shapefile of individual glacier polygons. Thorough inspection was undertaken to identify all glaciers positively and delineate their margins accurately. This included reviewing all sources of imagery in detail and distinguishing small glaciers from snowpatches by confirming the presence of visible crevasses and/or exposed ice. There were relatively few debriscovered glaciers, but, where these were encountered, accurate delineation was still possible with the use of the aerial photography. Based on the digital aerial photography, it was possible to define glaciers as small as $10^{2}-10^{3} \mathrm{~m}^{2}$ and to digitize their margins to within up to $\pm 5 \mathrm{~m}$ (for further discussion on the potential error associated with coregistration between the data sources, see DeBeer and Sharp, 2007). In instances where ice flow diverges into separate drainages, the glacier polygons were clipped manually along the flow divides identified from the DEM (valid for the initial time frame). For all glaciers, we determined how the glacier area changed between the 1951 and 2001 imagery. In order to achieve maximum confidence in our results for this task, it was necessary to refer visually to the British Columbia TRIM imagery shown in Google ${ }^{\mathrm{TM}}$ Earth, as very small features could be detected in this imagery and compared with the 1951 imagery. This allowed us to overcome the potential limitations of the coarser-resolution fused ETM+ imagery where snow, shadows or debris cover obscured the glacier margins.

\section{Topographic analysis}

A number of topographic indices were derived for each glacier using the shapefile polygons together with the DEM in ArcMap $^{\text {TM }}$ GIS. Parameters such as glacier area $\left(A ; \mathrm{m}^{2}\right)$ and perimeter $(P ; \mathrm{m})$ were derived directly from the polygons representing the 1951 glacier extents. Only glaciers with an initial surface area $<0.4 \times 10^{6} \mathrm{~m}^{2}$ (i.e. $0.4 \mathrm{~km}^{2}$ ) were included in the analysis. The area-weighted mean elevation of each glacier $(Z ; m)$ was determined for the 1951 spatial extent of the glacier polygons from the DEM and, in a similar manner, the average slope ( $\alpha$; degrees) and aspect ( $\omega$; degrees clockwise from north) of each glacier were determined using raster files derived from the DEM representing terrain slope (i.e. gradient) and aspect. Since aspect values are given in degrees clockwise from north, special care had to be taken in assigning mean values to glacier polygons that included both high and low values of aspect. In these cases, the appropriate value was interpreted manually using the aspect raster file and contour lines derived from the DEM. Potential error associated with the values of all of these parameters should be very small (i.e. within a few percent of their total ranges), because of the detailed methods used to delineate the glaciers and because the error associated with the DEM is not likely to be random. If the error in the DEM is directionally biased, individual gridcells would be offset from their true ground value, but the derived parameters involving slope or aspect would not be affected significantly. The estimated error of the DEM $( \pm 20 \mathrm{~m})$ is minimal in comparison to the range of elevations of these glaciers $(\sim 700 \mathrm{~m})$. The elevation and aspect of a glacier influence its mass balance primarily through their effects on energy receipt (i.e. air temperature, solar radiation receipt) and also through their influence on snow accumulation (i.e. increasing snowfall with elevation, and windward and leeward slope effects on snowfall and snow redistribution). The slope influences ice velocity and mass flux, and may also influence snow accumulation rates through its effect on avalanche transport of snow over the glacier surface.

Other relevant indices for glacier mass balance were derived from these initial parameters and/or the topography of the local areas surrounding individual glaciers. A compactness ratio $(C$; dimensionless) defined by the ratio of the area/perimeter ratio of a glacier to the area/perimeter ratio of a circle with the same area was derived following Allen (1998). This ratio is useful in describing the morphometry of a glacier as it relates to the confinement and potential mass inputs from avalanching from surrounding slopes (e.g. less compact glaciers may exhibit indented or irregular shapes and extend up feeding avalanche gulleys, or be elongated and occupy ledges and/or the base of steep slopes or cliffs). The potential effects of avalanching were further represented using indices of the upslope area and its average slope. A separate shapefile was created to represent upslope contributing areas above each of the glaciers. In this case, polygons were formed from the upslope edge of the glacier, the ridgeline above the glacier, and two paths, orthogonal to the contour lines, leading from the lateral extremes of the glacier to the ridgeline. The area occupied by the glacier within this zone was excluded, but in cases where other distinct glaciers were situated either partially or entirely within the upslope zone their area within this zone was included. Relative upslope area $\left(U_{A}\right.$; dimensionless) was then defined as the ratio of the upslope area to glacier surface area. Mean slope within the upslope contributing zone $\left(U_{\alpha}\right.$; degrees) was determined in the same manner as mean slope for the glacier polygons. These parameters provide an index of the potential contribution to the local mass balance from avalanching from slopes above the glacier, with larger and steeper upslope zones potentially providing greater mass inputs.

Finally, a parameter $\left(R_{\mathrm{s}}\right.$; dimensionless) was derived to represent the potential intensity of clear-sky direct-beam solar radiation inputs to the glacier surface during the ablation period. This involved taking the cosine of the incidence angle between the local glacier surface and the sun (following Garnier and Ohmura, 1970) at solar noon on 


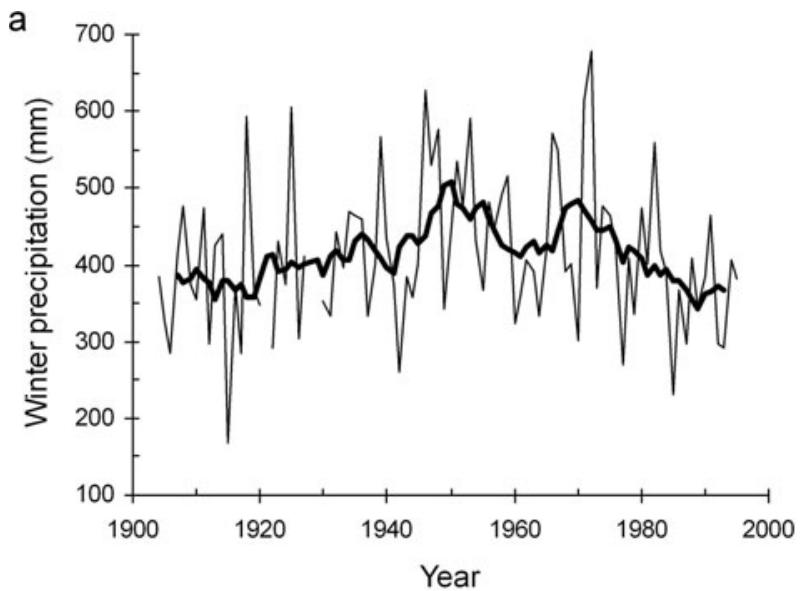

b

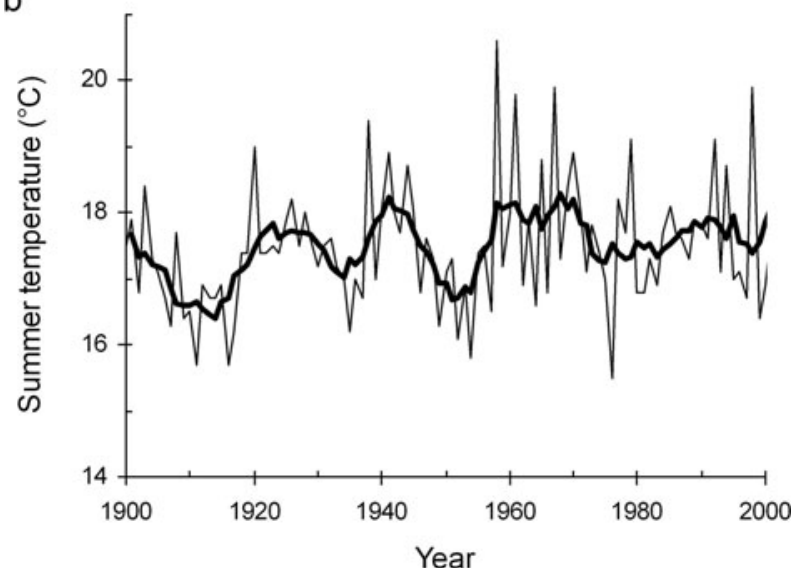

Fig. 2. Time series of (a) total winter (December-March) precipitation and (b) average summer (June-August) air temperature shown together with 7 year running averages (bold lines) for Revelstoke (station ID 1176749) (source: Historical Adjusted Climate Database for Canada; http://www.cccma.ec.gc.ca/hccd/).

1 August. For each glacier, this angle was determined using its average slope and aspect, together with the median latitude of the study region $\left(50.7^{\circ}\right)$ and the solar declination $\left(18.05^{\circ}\right)$ for this date and time. The resulting value was then modified to include the effects of shading by adjacent terrain. A hillshade raster was generated in $\operatorname{ArcMap}^{\mathrm{TM}}$ for the same solar geometry and was converted to a binary grid of 0 (shade) and 1 (no shade). The average value of this grid (equivalent to the fraction of non-shaded area) was then determined for each glacier and used to scale the directbeam radiation intensity term. This term is a useful approximation and serves as an index that should correlate well with incident radiation amounts obtained by integration over the ablation season and different times of day. Previous studies on mid-latitude alpine glaciers have found that net shortwave radiation is the dominant component in the surface energy balance during the ablation season (e.g. Greuell and Smeets, 2001; Oerlemans and Klok, 2002), so this parameter should provide an index for potential ablation rates on different glaciers during the summer.

\section{RESULTS AND DISCUSSION}

\section{Regional climate trends and glacier changes}

Figure 2 shows climatic trends for Revelstoke, British Columbia (Fig. 1; $50.97^{\circ} \mathrm{N}, 118.18^{\circ} \mathrm{W} ; 443 \mathrm{ma.s.l}$.) that are relevant for glacier mass balance in the region during the 20th century. At several times just prior to, and during, the study period conditions were likely to favor increasing regional glacier mass balance (i.e. more positive or less negative). These are times when total winter precipitation was unusually high and average summer temperatures were below average, such as the periods $\sim 1945-60$ and the late 1960 s and early 1970s. At other times, conditions were likely more conducive for decreasing mass balance in the region. The final two decades of the study period were characterized by considerably lower than average winter precipitation totals, beginning around the mid-1970s, and warmer than usual summer air temperatures. Mass-balance studies in the Canadian Rocky and southern Coast Mountains and the Pacific northwest of the United States record this decline in winter snowfall and show that it resulted in increasingly negative net mass balance due to the resulting more rapid rise of the transient summer snowline and earlier exposure of low-albedo glacier ice (Hodge and others, 1998; Bitz and Battisti, 1999; Moore and Demuth, 2001; Demuth and Keller, 2006).

Although these data are for a single site at low elevation and therefore may not be entirely representative of conditions in the vicinity of the glaciers, they provide a sense of recent climatic variability within the region. Although more detailed investigation of changes in the climate near the glaciers (e.g. accumulation at the equilibrium-line altitude (ELA); Braithwaite, 2008) and of the relationship between climate forcing and glacier response would be desirable, it would be difficult given the lack of available data and is beyond the objectives of the current study. Nevertheless, it is clear that recent conditions within the region have favored glacier decline. For instance, over the period 1951-2001, the larger glaciers (i.e. $0.4-5.0 \mathrm{~km}^{2}$ ) within the region (Blanket Glacier, $\sim 7.7 \mathrm{~km}^{2}$ in 1951 , is the largest ice mass in the region, but was divided into two separate drainages for accounting in this study) exhibited terminal retreat of up to nearly $2 \mathrm{~km}$ and net reduction of up to $60 \%$ of their initial area. These glaciers should have a response time in the order of decades (Jóhannesson and others, 1989; Harrison and others, 2001), implying that this decline is a response to recent climatic conditions within the region. There is no discernible spatial pattern of changes in glacier area and terminus position across the region, despite there being considerable differences between individual glaciers (Fig. 1; a pattern attributed primarily to differences in the local setting and morphology of the glaciers). This suggests that the recent declining tendency in winter precipitation and increasing summer air temperatures in the region have been distributed uniformly over the study area and that local characteristics have largely influenced the response of the glaciers to these trends.

The frequency distributions of glacier areas for both time periods (Fig. 3) are highly skewed towards the smaller glaciers in terms of their total numbers. Glaciers $<0.4 \times 10^{6} \mathrm{~m}^{2}$ in area represented $81 \%$ and $84 \%$ of the total population and $25 \%$ and $31 \%$ of the total area in 1951 and 2001, respectively. While four very small glaciers disappeared and were not counted in 2001, many larger glaciers retreated substantially and some became separated into two or more smaller glaciers, so that the number of glaciers in most of the smaller area classes either increased or remained unchanged. These results show a shift in the distributions of the glacier population and total glacier area towards smaller glaciers over this time period. 


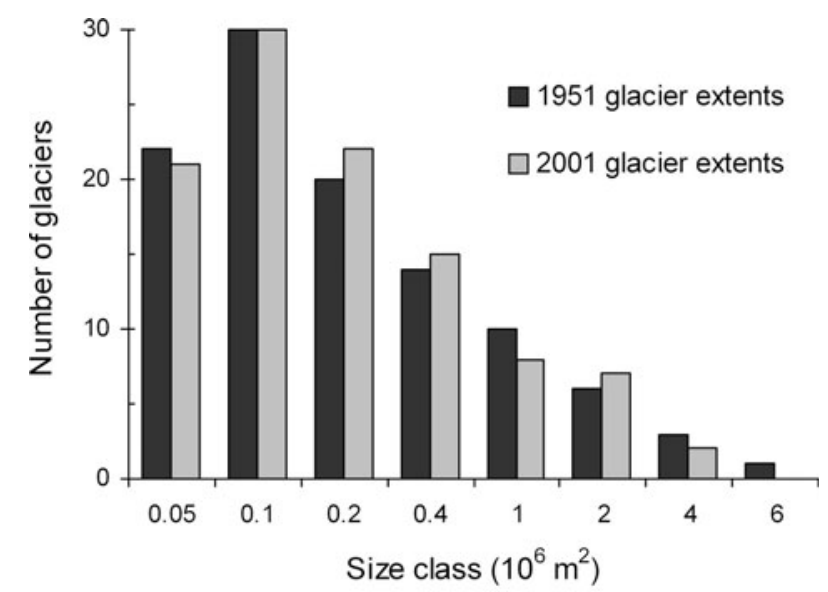

Fig. 3. Frequency histogram of glacier sizes within the study region for the 1951 and 2001 glacier extents. Size classes represent the maximum glacier area within each class.

\section{Topographic indices and local mass balance}

Of the glaciers in the study region, 86 had an initial area of $\leq 0.4 \times 10^{6} \mathrm{~m}^{2}$ as determined from the 1951 imagery. Table 1 gives summary statistical information for the various topographic and geometric indices calculated for these glaciers, and distinguishes between glaciers that disappeared or decreased in area and glaciers that either increased or did not change in area. Several differences are noted between the two populations. Glaciers that decreased in area or disappeared have lower mean values of elevation, surface slope and upslope zone steepness and higher mean values of upslope contributing area and potential direct-beam solar radiation than glaciers that maintained a constant area. However, given the small sample size we did not attempt to establish whether any of the differences between the two populations are statistically significant.

For aspect values, which are circular in nature, it is inappropriate to use ordinary linear statistics for analysis of these data (e.g. since $0^{\circ}$ is equivalent to $360^{\circ}$ ), so vector summation was used as an alternative. The mean aspect of each set of glaciers was determined by converting individual

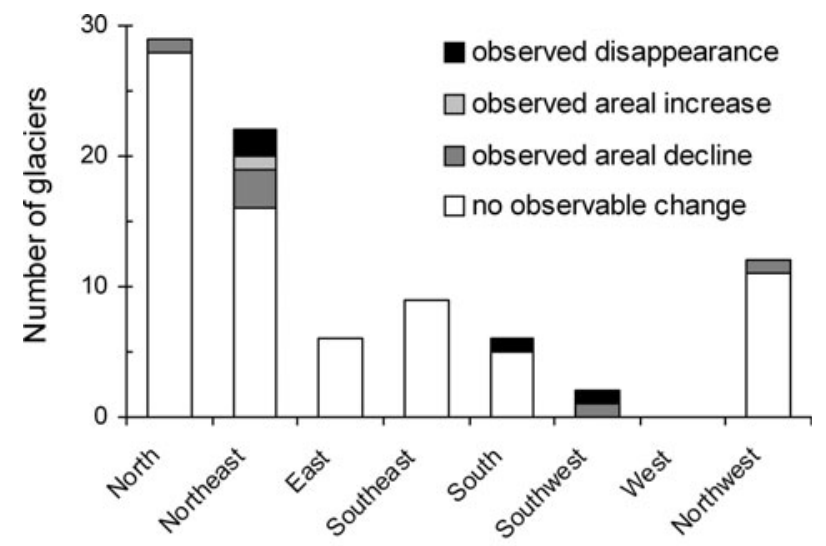

Aspect

Fig. 4. Frequency histogram of glaciers (initial area $<0.4 \times 10^{6} \mathrm{~m}^{2}$ ) within different aspect classes, indicating observed net changes of glaciers in these classes over the study period.

glacier aspects into unit vectors, summing the east and north components of these vectors and subsequently converting the direction of the resultant vector into a value of degrees clockwise from north. The strength of this vector was determined as the length of the resultant vector, expressed as a fraction of the total length of the individual component vectors (Evans, 1977, 2006). Vector strength provides a measure of the dispersion of glacier aspects, ranging from 0 for no favored direction to 1 for all glaciers having the same aspect. Table 1 shows that both populations are characterized by mean aspects slightly east of north; however, the vectors are concentrated in this direction for glaciers with areas that either did not change or increased in area (vector strength $=0.55$ ), whereas those of the glaciers that decreased in area or disappeared showed almost no favored direction (vector strength $=0.04$ ). The distribution of glacier aspects is shown as a frequency histogram in Figure 4, which also shows observed net changes in area of the glaciers within specific aspect classes. Glaciers with a northerly aspect are clearly the most common, but many glaciers also have aspects within the range east to south. Only two

Table 1. Summary of topographic and geometric indices for 86 glaciers with an initial area $<0.4 \times 10^{6} \mathrm{~m}^{2} . A$ is area, $P$ is perimeter, $Z$ is mean elevation, $\alpha$ is mean surface slope, $\omega$ is mean aspect, $C$ is compactness ratio, $U_{A}$ is relative upslope contributing area, $U_{\alpha}$ is mean slope in the upslope contributing zone and $R_{\mathrm{s}}$ is incident solar radiation index

\begin{tabular}{|c|c|c|c|c|c|c|c|c|}
\hline \multirow[b]{2}{*}{ Topographic parameter } & \multicolumn{4}{|c|}{$\begin{array}{l}\text { Glaciers that showed no net area change }(n=75) \text { or areal } \\
\qquad \text { increase }(n=1)\end{array}$} & \multicolumn{4}{|c|}{$\begin{array}{l}\text { Glaciers that showed net areal reduction }(n=6) \text { or } \\
\text { disappeared }(n=4)\end{array}$} \\
\hline & Mean & Std dev. & Max. & Min. & Mean & Std dev. & Max. & Min. \\
\hline$A\left(10^{6} \mathrm{~m}^{2}\right)$ & 0.11 & 0.09 & 0.38 & 0.01 & 0.12 & 0.10 & 0.33 & 0.03 \\
\hline$P(\mathrm{~m})$ & 1585 & 824 & 3988 & 368 & 1496 & 681 & 2491 & 694 \\
\hline$Z(\mathrm{~m})$ & 2350 & 156 & 2640 & 2049 & 2239 & 143 & 2440 & 1934 \\
\hline$\alpha\left(^{\circ}\right)$ & 33 & 8 & 55 & 8 & 19 & 6 & 25 & 6 \\
\hline$\omega\left(^{\circ}\right)$ & 24 & $0.55^{*}$ & - & - & 20 & $0.04 *$ & - & - \\
\hline C & 0.73 & 0.11 & 0.97 & 0.49 & 0.77 & 0.12 & 0.95 & 0.59 \\
\hline$U_{A}$ & 0.94 & 0.97 & 5.54 & 0 & 2.07 & 1.98 & 5.84 & 0.26 \\
\hline$U_{\alpha}\left({ }^{\circ}\right)$ & 40 & 9 & 57 & $15^{\dagger}$ & 27 & 9 & 42 & 12 \\
\hline$R_{\mathrm{s}}$ & 0.53 & 0.25 & 1.00 & 0.05 & 0.75 & 0.15 & 0.99 & 0.58 \\
\hline
\end{tabular}

*Values represent the vector strength as defined in the text.

$\dagger$ Value is the minimum slope in the upslope zone for glaciers that have non-zero relative upslope contributing areas (i.e. nine glaciers that showed no net areal change have no upslope contributing area). 

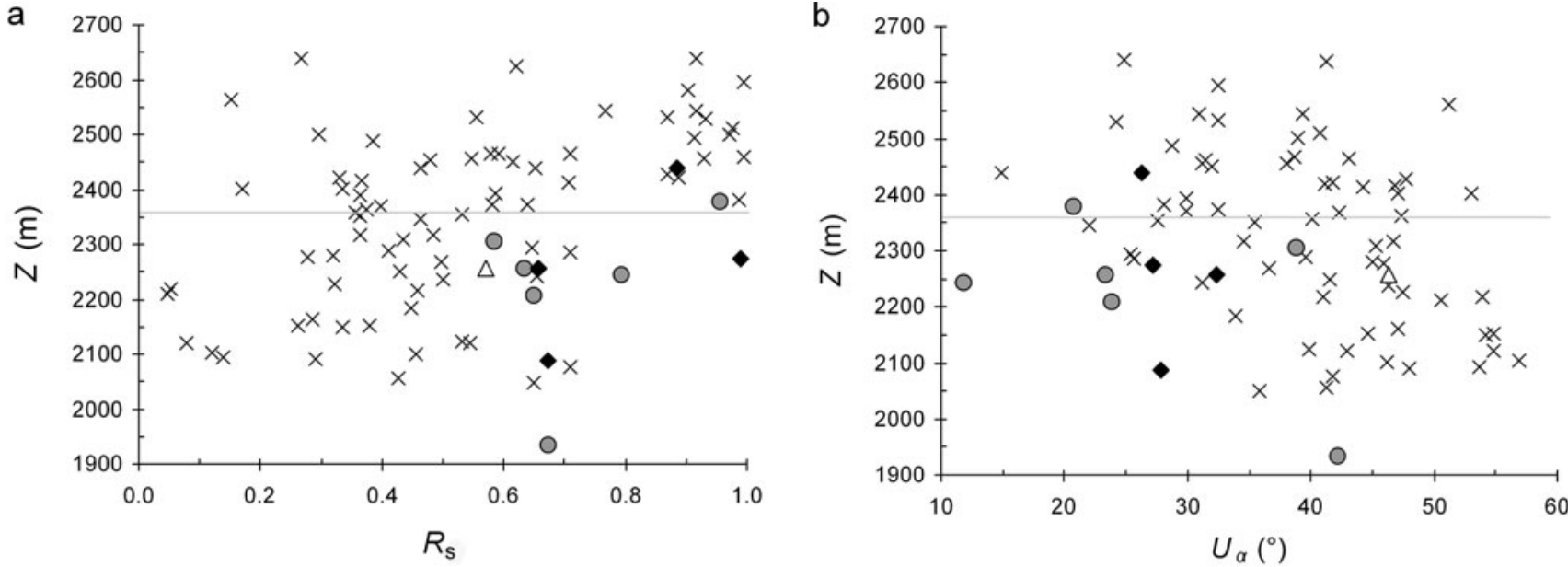

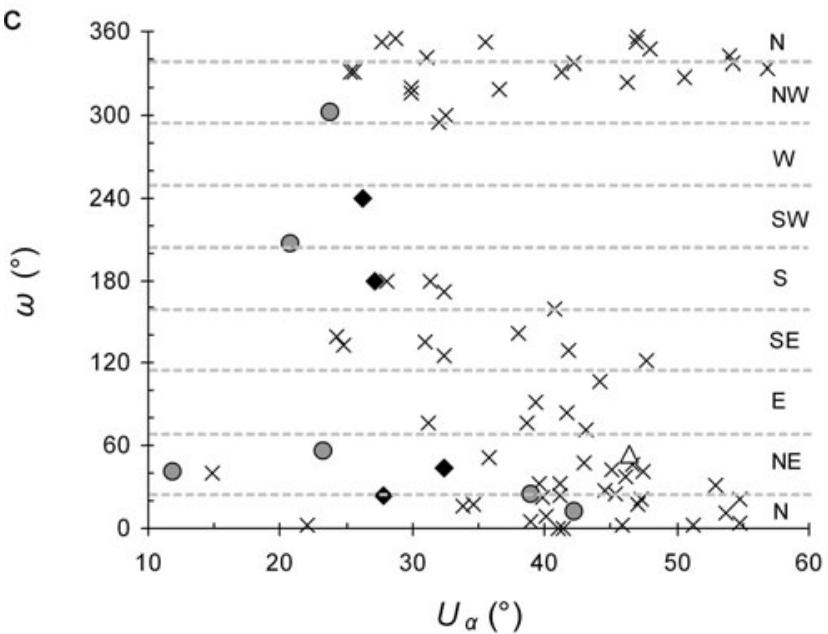

$\times$ no observable change

observed areal decline d

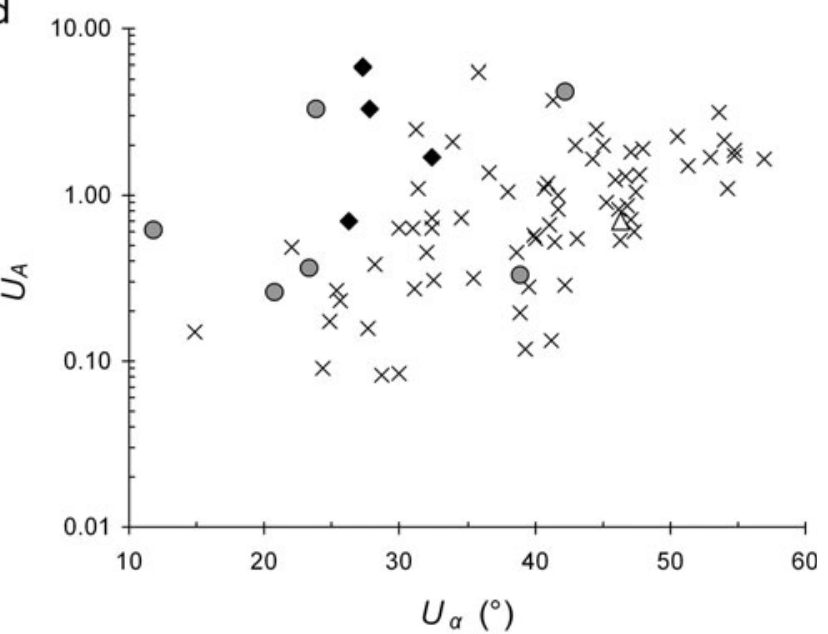

$\Delta$ observed areal increase

$\bullet$ observed disappearance

Fig. 5. Scatter plots showing relationships between selected topographic indices, indicating observed net changes of individual glaciers over the study period. $Z$ is mean elevation, $\omega$ is mean aspect, $U_{A}$ is relative upslope contributing area, $U_{\alpha}$ is mean slope in the upslope contributing zone and $R_{\mathrm{s}}$ is incident solar radiation index. The regional average long-term ELA is shown as the gray line in (a) and (b). The aspect classes of Figure 4 are shown in (c).

glaciers had an aspect of southwest or west and, of those, one shrank and one disappeared during the study period. These results indicate that sites facing towards the sun in the mid-afternoon are not favorable for glacier preservation. This tendency is likely due in part to more effective melting in the

Table 2. Spearman's rank correlation matrix of topographic and geometric indices. Bold values indicate significance at the $95 \%$ confidence level

\begin{tabular}{lrrrrrrrr}
\hline & $A$ & $P$ & $Z$ & $\alpha$ & $C$ & $U_{A}$ & $U_{\alpha}$ & $R_{\mathrm{s}}$ \\
\hline$A$ & $\mathbf{1 . 0 0}$ & & & & & & & \\
$P$ & $\mathbf{0 . 9 6}$ & $\mathbf{1 . 0 0}$ & & & & & & \\
$Z$ & 0.05 & -0.03 & $\mathbf{1 . 0 0}$ & & & & & \\
$\alpha$ & -0.20 & -0.13 & -0.09 & $\mathbf{1 . 0 0}$ & & & & \\
$C$ & $\mathbf{- 0 . 4 4}$ & $\mathbf{- 0 . 6 3}$ & $\mathbf{0 . 2 3}$ & -0.15 & $\mathbf{1 . 0 0}$ & & & \\
$U_{A}$ & $\mathbf{- 0 . 2 5}$ & -0.14 & $\mathbf{- 0 . 6 0}$ & $\mathbf{0 . 3 7}$ & -0.16 & $\mathbf{1 . 0 0}$ & & \\
$U_{\alpha}$ & $\mathbf{- 0 . 2 9}$ & $\mathbf{- 0 . 2 3}$ & $\mathbf{- 0 . 4 7}$ & $\mathbf{0 . 6 9}$ & $\mathbf{- 0 . 3 0}$ & $\mathbf{0 . 4 8}$ & $\mathbf{1 . 0 0}$ & \\
$R_{\mathrm{s}}$ & 0.12 & 0.06 & $\mathbf{0 . 3 9}$ & $\mathbf{- 0 . 7 0}$ & $\mathbf{0 . 2 6}$ & -0.18 & $\mathbf{- 0 . 8 8}$ & $\mathbf{1 . 0 0}$ \\
& & & & & & & &
\end{tabular}

afternoon when the combination of incident solar radiation and air temperature is at a maximum (Evans, 2006). Sites with a northern and eastern orientation are well suited for sheltering small glaciers, as suggested by the strong concentration of vectors in this direction for glaciers that underwent no net area change. Although these results are intuitive, there are several deviations from this generalization (e.g. the lack of a favored orientation for shrinking glaciers and the preservation of numerous glaciers with aspect values far from the mean), which are likely due to the combined effects of other factors affecting local mass balance, including those described previously in this paper.

Figure 5 and Table 2 provide details of the interrelationships between the various topographic and geometric indices calculated for individual glaciers. Spearman's rank correlation coefficients are used as a measure of the degree of association between these indices because they provide a simple non-parametric measure with few limiting assumptions. These are univariate associations, but are reasonable in this context because of the small sample size and the exploratory nature of this analysis. Many of the indices are significantly correlated with each other, which 
is to be expected given the inherent association between some of the parameters (e.g. area and perimeter for common shapes) and because some of the parameters were calculated in part using other parameters (e.g. compactness, which depends on perimeter and area). However, several of the significant correlations are not inherent and may have important implications for the local mass balance of many glaciers. The correlation between $R_{\mathrm{s}}$ and $Z$, for example, indicates that glaciers situated at lower elevations generally receive less clear-sky direct-beam solar radiation than glaciers at higher elevations. Atmospheric effects on incident radiation are not included in our model, but would tend to strengthen the positive association between $R_{\mathrm{s}}$ and $Z$ if they were included. This may help to explain the observed lack of area change of many of the glaciers, as glaciers in sites that are relatively exposed to the sun tend to be situated at higher elevations where air temperatures are cooler, thereby limiting ablation rates. Net longwave radiation is likely reduced on these higherelevation glaciers due to reduced air mass above them and less obstructed local horizons (e.g. Strasser and others, 2004), as suggested by the strong negative association between $Z$ and $U_{A}$. Further, these high-elevation glaciers may retain snow cover later in the summer due to higher snow accumulation and reduced melt rates, which act to maintain a relatively high albedo and limit the net shortwave radiation receipt. In contrast, glaciers situated at relatively low elevations are sheltered to a greater extent from direct solar radiation. This tends to create a local microclimate that is cooler and more favorable for the preservation of ice. It has been suggested that smaller glaciers, with an inherently greater area-to-volume ratio, should shrink faster than larger glaciers under the same ablation rate (Granshaw and Fountain, 2006). The topographic settings of many of the very small glaciers in this study indicate that ablation rates at a given elevation on these glaciers are likely much less than those at equivalent elevations on the larger and more exposed glaciers.

Ice may also persist at elevations far below the regional ELA, in part due to enhancement of accumulation to levels that exceed potential ablation for that altitude (Kuhn, 1995). Wind drifting and avalanches, for example, may considerably increase the local snow accumulation relative to winter precipitation alone, such that accumulation on small sheltered glaciers can be almost invariant in response to variations in direct snowfall (e.g. Hoffman and others, 2007). Several of the topographic and geometric indices derived in this study are useful for examining differences in the local accumulation characteristics. Table 2 shows significant rank correlations between the indices representing elevation, compactness, upslope zone steepness and relative area, and potential direct-beam solar radiation. These interrelationships suggest that glaciers situated at relatively low elevations are generally less compact in shape, are located beneath relatively steeper slopes and tend to have more extensive contributing areas above their upper margins than glaciers at higher elevations. Such glaciers commonly have more complex and elongated shapes, occupy ledge systems and the shaded edges of cirque backwalls, and have upper margins that extend up feeding avalanche gulleys. In general, they do not extend far beyond the shelter of the cirque backwalls along their flow trajectory (see Fig. 7a below). This suggests that there may be large gradients in ablation rates with distance from the cirque backwalls that are due to increasing direct-beam solar radiation. Since these glaciers likely receive enhanced mass inputs and are relatively more sheltered from direct solar radiation, they may be insensitive to the recent decline in winter precipitation that has been observed in this region.

Figure 5 provides additional insight into how the topographic setting of individual glaciers has influenced their response to recent climatic variations. In Figure $5 \mathrm{a}$, all of the glaciers that decreased in area or disappeared during the study period plot within the lower right quadrant of the graph. Most of these glaciers are situated up to several hundred meters below the regional average long-term ELA $(\sim 2360 \mathrm{~m})$ and have $R_{\mathrm{s}}$ values $>\sim 0.6$. (The regional average long-term ELA was estimated as the average elevation where contour lines change from concave to convex down-valley (e.g. Leonard and Fountain, 2003), for glaciers with an initial area $>\sim 0.8 \times 10^{6} \mathrm{~m}^{2}$ in the region. This provides an approximate measure of the long-term average ELA that would have persisted over several decades before the time of initial image acquisition.) This suggests that these glaciers are subjected to higher air temperatures and solar radiation receipts than the glaciers that maintained their areas. Concomitantly, these glaciers are situated below slopes that are less steep than $30^{\circ}$ on average (Fig. 5b-d), which are unlikely to contribute significant amounts of snow to the glacier surface by avalanching and which leave the glaciers more reliant on local winter precipitation for nourishment. The two glaciers that were situated below relatively steeper slopes (i.e. $\sim 40^{\circ}$ ) and underwent a reduction in area were either located at extremely low elevation (Fig. 5b) or had a relatively small contributing upslope area (Fig. $5 \mathrm{~d}$ ). Thus, the glaciers that decreased in area or disappeared have likely responded more to increasing air temperatures and/or decreasing winter precipitation because they were initially situated in locations that are marginal for ice preservation.

A number of glaciers are situated within sites that are unlikely to receive enhanced inputs from avalanches (i.e. those in the lower left quadrant of Fig. 5d), and many of these maintained their area over the study period. These glaciers are typically found at higher elevations (Fig. 5b) and have aspect values in the range of northwest to southeast (i.e. $<157.5^{\circ}$ and $>292.5^{\circ}$; Fig. $5 \mathrm{c}$ ). Most glaciers facing in these directions occupy leeward positions that are sheltered from westerly and southwesterly winds (Fig. 1), and those at high elevations are likely sustained predominantly by wind drift in addition to direct snowfall. Previous authors have used quantitative approaches to characterize potential accumulation on small glaciers and perennial snowpatches (e.g. Mitchell, 1996; Allen, 1998; Carr and Coleman, 2007), but these are not likely to be informative here since the approaches relate accumulation to upwind plateau surface area or site elevation in relation to elevation in the upwind direction. The terrain here does not include large plateaus upwind of the glaciers. The dominant control on winddrifted snow deposition on high-elevation glaciers here is most likely airflow separation over the sharply crested terrain characteristic of the region (Barry, 1992), which is not dependent on relative mean elevation in a specified direction or upwind contributing source area. Further, some techniques require information on ablation at the ELA, which is difficult to obtain (e.g. ELAs are difficult or impossible to determine on these very small glaciers), and cannot distinguish between snow-blow and avalanching (Carr and Coleman, 2007). 
a

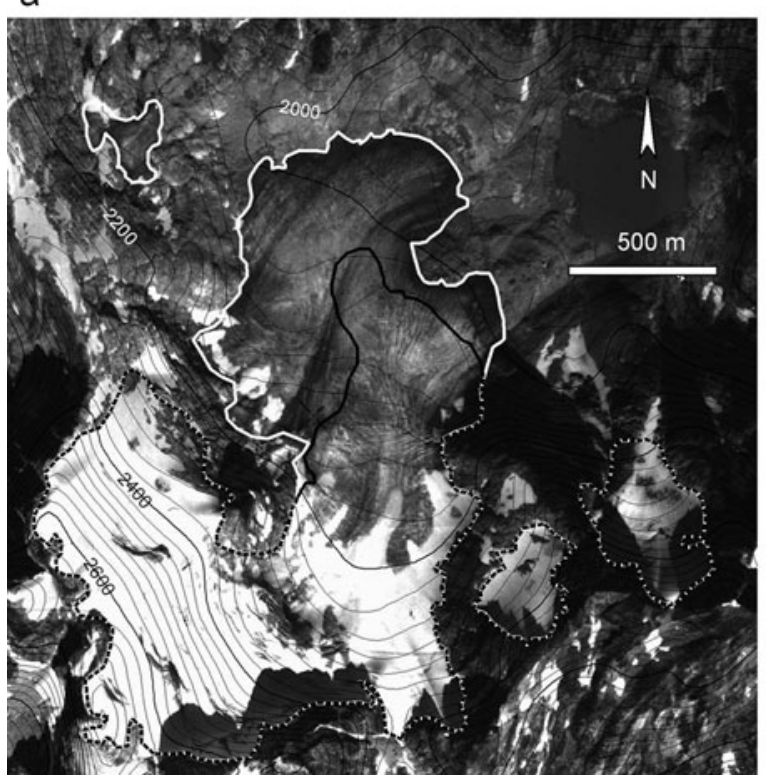

b

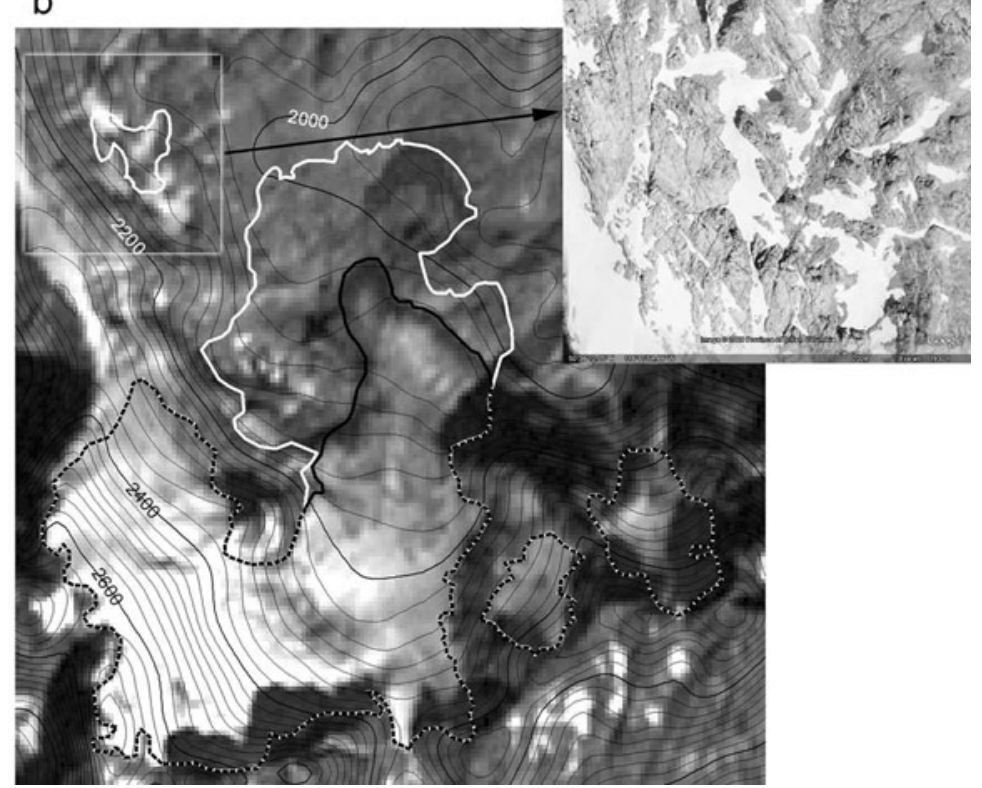

Fig. 6. Comparison of glacier margins between 1951 and 2001 shown over (a) British Columbia Government aerial photograph and (b) Landsat 7 ETM+ image (inset in (b) is part of the TRIM orthophoto mosaic shown in Google ${ }^{\mathrm{TM}}$ Earth). White, black (in bold) and dashed lines represent ice margins in 1951, 2001 and both time periods (i.e. unchanged margins), respectively. Contour lines ( $25 \mathrm{~m}$ interval) derived from the DMTI Spatial Inc. DEM are also shown in the figure. The location of these images within the study region is indicated in Figure 1.

\section{Other local site characteristics}

All of the glaciers that disappeared over the study period share an attribute that was not addressed by the topographic analysis. In contrast to all other small glaciers, which were predominantly snow-covered, these glaciers had little or no snow cover in the 1951 aerial photography. Glaciers that disappeared were typically located in close proximity (i.e. horizontally and vertically) to areas in which there was extensive wastage of larger glaciers between image acquisition dates. This may indicate that these were relict glaciers, out of equilibrium with climatic conditions prior to, and during, the study period. Figure 6 provides an example where the small glacier in the top left-hand corner of the 1951 image had almost no snow cover, was relatively distorted in shape and was situated at a lower elevation than the other small glaciers in the lower right-hand corner of the images. This glacier was located adjacent to the extensive ablation area of the larger glacier and was situated in a site that appears previously to have been a contributing source area for the large glacier. Thus, this glacier seems to be a remnant of a former larger glacier system from which it had become detached before the time of initial image acquisition. At the beginning of the study period, this glacier had no discernible accumulation area and appeared to be an isolated ice mass left to melt in situ. Figure 6 (as well as Figure 7) also shows how the highresolution TRIM imagery is essential in distinguishing glacial ice from snowpatches in order to determine reliably the changes in these glaciers.

Very few glaciers advanced or increased in area. This is likely because regional climatic conditions were conducive to declining tendencies of mass balance during most of the study period. There are also several topographic factors that may partly explain the observed lack of areal increase of most of the glaciers. In many cases, glaciers are prevented from advancing far beyond cirque backwalls and sheltered areas due to the high gradients in energy receipt (i.e. direct solar radiation, temperature) away from these locations, which act to limit the extent of the glacier. The margins of many of the glaciers analyzed in this study are topographically constrained and they terminate on very steep slopes and cliffs. In these instances, an increase in accumulation and local mass balance typically leads to an increase in ice advection and/or loss by avalanching and ice calving to locations far below where the ice/snow melts in situ or contributes to other glaciers. Thus, the margins of many of these glaciers likely do not change on a year-to-year basis. In addition, small moraines and protalus/pronival ramparts (i.e. small accumulations of fallen rock debris) at the lower margins of the glaciers may form a barrier to ice movement and act as dams for avalanches (Kuhn, 1995). If the glaciers gain mass such that they overtop the crests of these ridges, subsequent avalanches will continue past the glacier margin and be lost to local mass balance. Such features were indeed observed in front of some of the small glaciers in this study, indicating that significant advance beyond these limits is physically unlikely.

Figure 7 provides examples of several of the features discussed in this paper. In Figure 7a it is clear that the glaciers are sustained by avalanching from upper contributing slopes and are highly sheltered from direct solar radiation (especially the lower-elevation glacier at the right). Several protalus/pronival ramparts can be seen, which act to trap snow from avalanching. Figure $7 \mathrm{~b}$ shows some highelevation glaciers occupying northeast-facing positions that terminate on steep slopes or cliffs. Note the relative confinement of all glaciers and also the increasingly compact shape and evidence of wind-blown snow accumulation (i.e. cornices and drifts) on glaciers at higher elevations in general. Numerous snowpatches can also be seen in these images, but are readily distinguished from glaciers in most instances by the absence of crevasses and visible ice. 


\section{CONCLUSIONS}

Inspection of relatively snow-free remotely sensed imagery acquired during the late summer of 1951, 2001 and 2004 over a small region of the Monashee Mountains in the southeast interior of British Columbia showed that relatively few small glaciers underwent any observable net change in area over the $\sim 50$ year period. It is a reasonable (though unproven) inference that most of these glaciers have not changed appreciably in thickness either. Most of the glaciers are situated in locations that favor their preservation (i.e. they are sheltered from direct solar radiation or are located at relatively high elevations and they typically reside in sites that receive enhanced mass inputs from either avalanching from upper contributing slopes or wind drift onto leeward slopes). Many of the small glaciers in sites more unfavorable for ice preservation either retreated or disappeared during the study period. Thus, the local topographic setting of very small glaciers has a significant effect on their response to climate change and, as noted elsewhere, these glaciers may not provide a reliable indicator of such change (e.g. Kuhn, 1995). All available data suggest that the mass balance of larger glaciers in the region has been strongly negative and that glacier retreat has been widespread. These results suggest that most of the very small glaciers in this region, which are generally confined to sites where the local controls on mass balance are, at best, poorly coupled to the regional climate, may already have retreated as far as they are likely to under the climatic conditions of the late 20th century.

On scales larger than a single mountain range, glaciers such as the ones described in this study comprise a significant fraction of the total population of global alpine glaciers. Calculations of sea-level rise and regional waterresource management rely on stochastic scaling paradigms that require understanding of the distribution of regional- or global-scale glacier properties (Bahr, 1997; Bahr and Meier, 2000). Therefore, whether small glaciers globally are changing in a way similar to those in the Monashees, or in a way similar to those in the Alps and in other parts of western North America (where the smaller glacier classes exhibit greater proportional area decrease than do the larger classes; Paul and others, 2004; Granshaw and Fountain, 2006; Demuth and others, 2008), remains an important question to be answered. The results of this study suggest that genuine differences in the local setting and morphology of individual glaciers may help to partly explain the contrasting results from different regions and further that the topographic setting of glaciers may be useful in predicting their future response to climate change. As many glaciers undergo areal decline in response to less favorable climate conditions, they may retreat into more sheltered locations where a new equilibrium condition can be established, notwithstanding the rate of climatic change forecast for the next century. Thus, the possibility that ongoing glacier shrinkage will not necessarily result in total glacier disappearance should be recognized.

\section{ACKNOWLEDGEMENTS}

We thank the NHRI for providing access to the aerial photography archived as part of Canada's National Glacier Inventory. Funding was provided in part by the Natural Sciences and Engineering Research Council of Canada
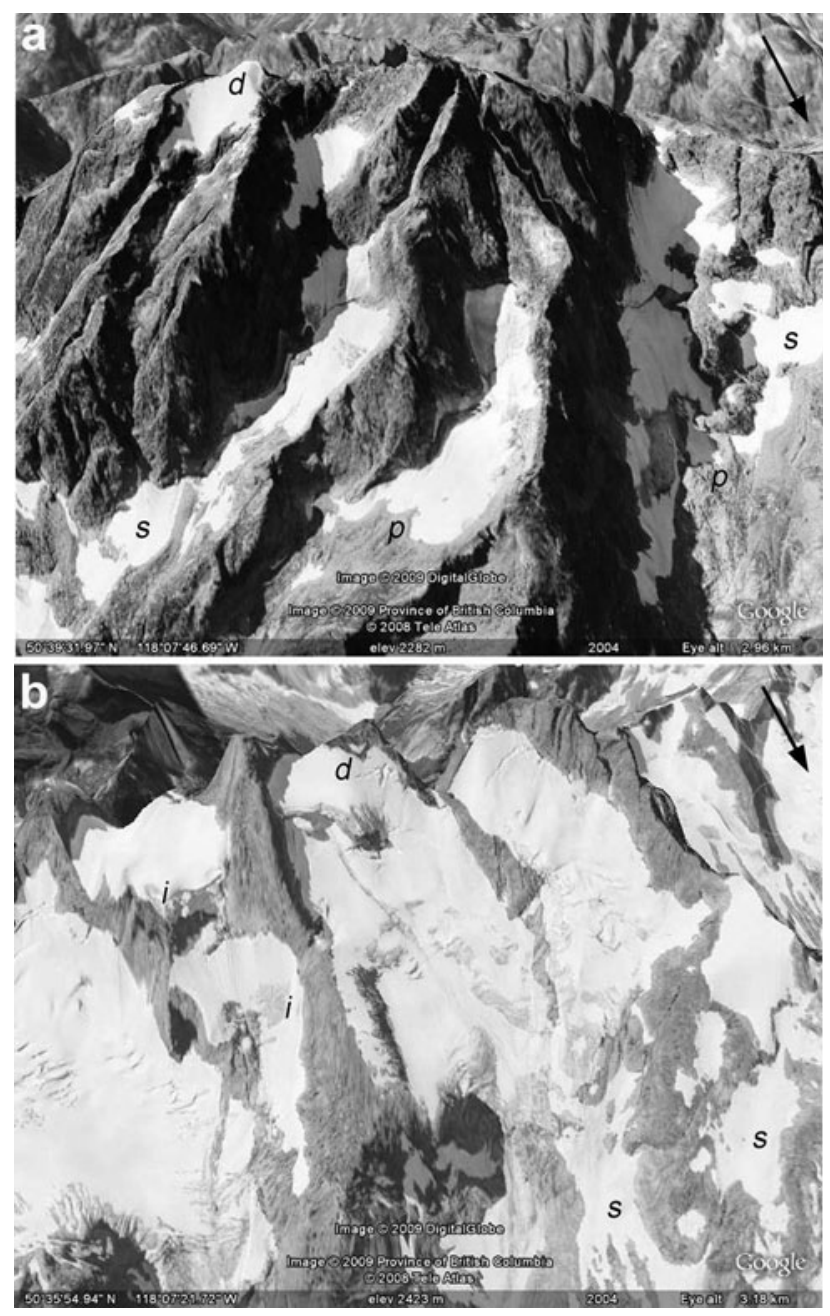

Fig. 7. Example images of the TRIM orthophoto mosaic viewed in 3-D with Google ${ }^{T M}$ Earth, showing examples of several features of the small glaciers within the study region ( $p$ : protalus/pronival ramparts; d: snowdrifts and cornices; i: visible ice and crevasses; s: snowpatches). Arrows in the top right corners indicate the direction of north. The locations of these images within the study region are indicated in Figure 1.

(NSERC) through Discovery Grants to M.J.S. and scholarship support to C.M.D. We also thank G. Cogley, I. Evans and T. Condom for insightful comments that greatly improved the manuscript.

\section{REFERENCES}

Allen, T.R. 1998. Topographic context of glaciers and perennial snowfields, Glacier National Park, Montana. Geomorphology, 21(3-4), 207-216.

Bahr, D.B. 1997. Global distributions of glacier properties: a stochastic scaling paradigm. Water Resour. Res., 33(7), 1669-1679.

Bahr, D.B. and M.F. Meier. 2000. Snow patch and glacier size distributions. Water Resour. Res., 36(2), 495-501.

Barry, R.G. 1992. Mountain weather and climate. Second edition. London and New York, Routledge.

Bitz, C.C. and D.S. Battisti. 1999. Interannual to decadal variability in climate and the glacier mass balance in Washington, western Canada, and Alaska. J. Climate, 12(11), 3181-3196.

Braithwaite, R. 2008. Temperature and precipitation climate at the equilibrium-line altitude of glaciers expressed by the degree-day factor for melting snow. J. Glaciol., 54(186), 437-444. 
Braithwaite, R.J. and S.C.B. Raper. 2002. Glaciers and their contribution to sea level change. Phys. Chem. Earth, 27(32-34), 1445-1454.

Carr, S. and C. Coleman. 2007. An improved technique for the reconstruction of former glacier mass-balance and dynamics. Geomorphology, 92(1-2), 76-90.

DeBeer, C.M. and M.J. Sharp. 2007. Recent changes in glacier area and volume within the southern Canadian Cordillera. Ann. Glaciol., 46, 215-221.

Demuth, M.N. and R. Keller. 2006. An assessment of the mass balance of Peyto Glacier (1966-1995) and its relations to recent and past-century climatic variablity. In Demuth, M.N., D.S. Munro and G.J. Young, eds. Peyto Glacier - one century of science. Saskatoon, Sask., National Hydrological Research Institute, 83-132. (NHRI Scientific Report 8.)

Demuth, M.N. and 6 others. 2008. Recent and past-century variations in the glacier resources of the Canadian Rocky Mountains - Nelson River system. In Bonardi, L., ed. Terra Glacialis Edizione Speciale: Ghiacciai montaini e cambiamenti climatici nell'ultimo secolo/Mountain glaciers and climate changes of the last century. Milan, Servizio Glaciologico Lombardo, 27-52.

Dyurgerov, M.B. and M.F. Meier. 2005. Glaciers and the changing Earth system: a 2004 snapshot. Boulder, CO, University of Colorado. Institute of Arctic and Alpine Research. (INSTAAR Occasional Paper 58.)

Evans, I.S. 1977. World-wide variations in the direction and concentration of cirque and glacier aspects. Geogr. Ann., 59A(3-4), 151-175.

Evans, I.S. 2006. Local aspect asymmetry of mountain glaciation: a global survey of consistency of favoured directions for glacier numbers and altitudes. Geomorphology, 73(1-2), 166-184.

Farley, A.L. 1979. Atlas of British Columbia: people, environment, and resource use. Vancouver, B.C., University of British Columbia Press.

Fountain, A.G. and W. Tangborn. 1985. The effects of glaciers on streamflow variations. Water Resour. Res., 21(4), 579-586.

Garnier, B.J. and A. Ohmura. 1970. The evaluation of surface variations in solar radiation income. Solar Energy, 13(1), 21-34.

Granshaw, F.D. and A.G. Fountain. 2006. Glacier change (19581998) in the North Cascades National Park Complex, Washington, USA. J. Glaciol., 52(177), 251-256.

Greuell, W. and P. Smeets. 2001. Variations with elevation in the surface energy balance on the Pasterze (Austria). J. Geophys. Res., 106(D23), 31,717-31,727.
Harrison, W.D., D.H. Elsberg, K.A. Echelmeyer and R.M. Krimmel. 2001. On the characterization of glacier response by a single time-scale. J. Glaciol., 47(159), 659-664.

Hodge, S.M., D.C. Trabant, R.M. Krimmel, T.A. Heinrichs, R.S. March and E.G. Josberger. 1998. Climate variations and changes in mass of three glaciers in western North America. J. Climate, 11(9), 2161-2179.

Hoffman, M.J., A.G. Fountain and J.M. Achuff. 2007. 20th-century variations in area of cirque glaciers and glacierets, Rocky Mountain National Park, Rocky Mountains, Colorado, USA. Ann. Glaciol., 46, 349-354.

Holland, S.S. 1976. Landforms of British Columbia: a physiographic outline. Victoria, B.C., Department of Mines and Petroleum Resources. (Bulletin 48.)

Jóhannesson, T., C.F. Raymond and E.D. Waddington. 1989. A simple method for determining the response time of glaciers. In Oerlemans, J., ed. Glacier fluctuations and climatic change. Dordrecht, etc., Kluwer Academic Publishers, 343-352.

Kuhn, M. 1995. The mass balance of very small glaciers. Z. Gletscherkd. Glazialgeol., 31(1-2), 171-179.

Leonard, K.C. and A.G. Fountain. 2003. Map-based methods for estimating glacier equilibrium-line altitudes. J. Glaciol., 49(166), 329-336.

Meier, M.F. and 7 others. 2007. Glaciers dominate eustatic sealevel rise in the 21st century. Science, 317(5841), 1064-1067.

Mitchell, W.A. 1996. Significance of snowblow in the generation of Loch Lomond Stadial (Younger Dryas) glaciers in the western Pennines, northern England. J. Quat. Sci., 11(3), 233-248.

Moore, R.D. and M.N. Demuth. 2001. Mass balance and streamflow variability at Place Glacier, Canada in relation to recent climate fluctuations. Hydrol. Process., 15(18), 3472-3486.

Oerlemans, J. and E.J. Klok. 2002. Energy balance of a glacier surface: analysis of automatic weather station data from the Morteratschgletscher, Switzerland. Arct. Antarct. Alp. Res., 34(4), 477-485.

Paul, F., A. Kääb, M. Maisch, T. Kellenberger and W. Haeberli. 2004. Rapid disintegration of Alpine glaciers observed with satellite data. Geophys. Res. Lett., 31(21), L21402. (10.1029/ 2004GL020816.)

Strasser, U., J. Corripio, F. Pellicciotti, P. Burlando, B. Brock and M. Funk. 2004. Spatial and temporal variability of meteorological variables at Haut Glacier d'Arolla (Switzerland) during the ablation season 2001: measurements and simulations. J. Geophys. Res., 109(D3), D3103 (10.1029/2003JD003973.) 